\title{
O IMAGINÁRIO NO CORDEL ANTONIO CONSELHEIRO: O PROFETA DO SERTÃO
}

\section{THE IMAGINARY ON CORDEL LITERATURE ANTONIO CONSELHEIRO:O PROFETA DO SERTÃO}

Geam Karlo-Gomes ${ }^{1}$

ORCID: http://orcid.org/0000-0001-9569-1497

\begin{abstract}
Resumo: Esta abordagem, numa perspectiva da psicologia analítica e do imaginário coletivo, perfaz uma leitura mítico-arquetípica do imaginário no cordel. O corpus de análise é um cordel brasileiro, intitulado Antonio Conselheiro: o profeta do sertão (RINARÉ, 2015). No intuito de interpretar os mitos e arquétipos que organizam a imagem messiânica de Antonio Conselheiro nessa poética de Rinaré, notam-se: o mitologema da Criança Divina como marco originário de sua trajetória mística; o arquétipo do Velho Sábio em suas virtudes como um conselheiro espiritual; e o mito do Salvador, acentuando sua figura de esperança para um destino com bem-aventuranças em Canudos.
\end{abstract}

Palavras-chave: Arquétipos. Mitos. Cordel.

\begin{abstract}
Based on a perspective of analytical psychology and the collective imagination, this approach makes a mythical and archetypal reading of the imaginary in the cordel literature. The object of analysis is a Brazilian cordel literature, whose title is Antonio Conselheiro: o profeta do sertão (RINARÉ, 2015). In order to interpret the myths and archetypes that organize Antonio Conselheiro's messianic image in Rinaré's poetics, the following can be noted: the mythology of the Divine Child as an original landmark in his mystical trajectory; the Wise Old Man archetype in his virtues of a spiritual counsellor; and the myth of the Savior, accentuating his figure as hope for a destiny with beatitudes in Canudos.
\end{abstract}

Keywords: Archetypes. Myths. Cordel literature.

\footnotetext{
${ }^{1}$ Professor do Programa de Pós-Graduação em Culturas Africanas, da Diáspora e dos Povos Indígenas, da UPE; e do Programa de Pós-graduação em Educação, Cultura e Territórios Semiáridos. PPGESA, da UNEB. Lattes: http://lattes.cnpq.br/6941717348545116 E-mail: geam.k@upe.br
} 
Há muito tempo, há muito tempo,

Criado por Deus,

Criado por Pajana,

Um menino vivia órfão.

Sem alimentos para comer,

Sem roupas para vestir,

Assim vivia ele.

Ali não há mulher que case com ele.

Uma raposa veio até ele;

A raposa falou com o jovem:

Como te tornarás um homem?

Perguntou-lhe.

$O$ menino disse:

Como me tornarei um homem,

Nem eu mesmo sei!

(Conto da floresta negra dos tártaros da região Altai)

\section{O universo imaginário no cordel}

Um mergulho na história da colonização do Brasil pode auxiliar no resgate da origem do termo "literatura de cordel". Tudo inicia quando nem se imaginava as facilidades de publicação que se tem hoje. Sem a eletricidade, a tipografia, e muito menos a imprensa moderna, a forma mais rápida de comunicação eram os pequenos folhetos, pendurados em cordões para serem vendidos nas feiras. Daí o termo "cordel". Aquilo que chamamos de literatura de cordel no Brasil (o cordel brasileiro) difere nitidamente do produto que se originou em Portugal. Para Diegues Junior (1973), o nome é assinalado por Teófilo Braga, ao fazer referência ao pitoresco "literatura de cordel". Isso em decorrência da forma como os folhetos eram apresentados ao público: em barbantes.

A literatura marcada por métricas e rimas próprias, de forte tradição regional, dotada de heranças culturais, artísticas e religiosas, inscreve-se, entre outras formas, por meio de narrativas $^{2}$ que não fogem às marcas da cultura política. Isso porque, por meio do resgate ou (re) invenções de histórias, os cordéis nascem mergulhados nas mais densas inquietações de seu contexto histórico-social. Entre os temas, podem-se encontrar: problemáticas sociais,

${ }^{2}$ É preciso considerar que além da narrativa há também a modalidade da cantoria, a descritiva, que marca o gênero literário drama (LUCIANO, 2012, p. 44). 
biografias, religião, fatos históricos, narrativas bizarras, crendices, estereótipos, temas messiânicos, entre tantos outros.

Mesmo que o cordel tenha tomado dimensões gigantescas em torno de sua abrangência temática - transposição da literatura universal e dos tidos clássicos da literatura brasileira, apontamentos em torno da política atual, de grandes nomes da literatura, da música, do cinema, entre tantas áreas -, há destaque também para questões atuais, filosóficas, da educação, da mídia, da história em geral. Trata-se da recorrência de uma fonte inesgotável, sendo reeditada, reescrita, reinventada e que insiste em perdurar. São temas míticos, lendários, sobrenatural, aventuras, revoluções, heróis, festas populares ou religiosas, crendices populares, entre outros, que escapam tão somente às especulações racionais. Entretanto, não podem ser mensurados apenas pelo valor do irreal. Do contrário, cria uma atmosfera real, representativa, repleta de múltiplas e emblemáticas representações que englobam o imaginário no cordel.

Convém, nesse sentido, considerar o imaginário não simplesmente como ficção, como irrealidade. O imaginário é real: uma fonte que alimenta nossa atividade imaginativa ao mesmo tempo em que dela se apropria. O imaginário contempla as subjetividades e compõe um universo coletivo. Nesse sentido, é o que Michel Maffesoli constitui como "estado de espírito de um grupo, de um país, de uma Estado-nação, de uma comunidade" (MAFFESOLI, 2001, p. 76). O imaginário individual corresponde ao imaginário coletivo quando apresenta tanto o onírico, o mítico, a fantasia, o viés imaginativo e afetivo, o irreal; mas também o racional e o aceitável.

Nos cordéis - mesmos aqueles que contemplam os fatos históricos ou problemáticas sociais -, percebe-se a presença de elementos que se distanciam das "formulações demonstrativas", isto é, sobre as quais se atribui um valor de atemporalidade (GIRARDET, 1987). Uma interpretação que, a princípio, constitui-se no fato de essas obras germinarem das mais densas potências oníricas. Trata-se de uma atmosfera que escapa apenas a típica racionalidade aparente da marca da cultura política, visto que abrange a presença de uma “notável efervescência mitológica” (GIRARDET, 1987, p. 9-11).

Assim, reunindo narrativas, dramas, o lírico, os cordéis brasileiros remontam a dinâmica sociocultural com toda a memória da humanidade. Tomando de empréstimos "motes" como marcos históricos, o folclore, fatos científicos, fatos do cotidiano etc., o cordel traz pela experiência da novidade da arte em versos, uma aura imaginária que pode ser lida 
por meio da leitura das imagens simbólicas coletivas, estruturadas por meio de arquétipos e mitos.

\section{Arquétipos e mitos}

O vasto cordel brasileiro, repleto de personagens históricos, emblemáticos, inusitados, do cotidiano, refletem, além das memórias pessoais, aquelas que são (re)criadas a partir do inconsciente, dotados de tijolos mitológicos: os arquétipos. Carl Gustav Jung compreende arquétipo diferente do conceito já utilizado na Antiguidade, que é semelhante a “ideia" no pensamento platônico (JUNG, 2012). Isso porque, diferente de Platão, a psicologia profunda provém da compreensão de que o arquétipo é herdado por meio da influência do inconsciente coletivo.

Diferente de S. Freud - cuja perspectiva teórica considerava o inconsciente apenas como os conteúdos reprimidos, recalcados, e por isso, exclusivamente pessoal -, para C. G. Jung, o inconsciente possui duas camadas: uma mais superficial, chamada de inconsciente pessoal; e outra mais profunda, denominada de inconsciente coletivo (JUNG, 2012). Esse é chamado de coletivo em detrimento de que é universal, isto é, seus conteúdos são idênticos em todos indivíduos e não possuem origem em aquisições derivadas de experiências pessoais. Do contrário, são tipos de "substratos psíquicos comuns de natureza psíquica suprapessoal que existe em cada ser humano" (JUNG, 2012, p.12). São exemplos de arquétipos: a Persona, Animus, Anima, Sombra, Grande Mãe, Pai, Self, Velho Sábio, PuerSenex, entre outros.

No mundo moderno, os estudos da psicologia junguiana têm identificado novas contribuições para leitura da psique humana: os arquétipos das Deusas na mitologia grega BOLEN (1990); (WOOLGER; WOOLGER, 20017); os referenciais psicológicos em ambientes empresariais (MARK; PERSON, 2003), e essa lista não para aqui.

Convém, então, afirmar que os estudos da psique são fundamentais para compreender o homem e sua relação com a ancestralidade e com o imaginário coletivo. Assim, é possível notar que existem analogias entre as imagens oníricas provenientes do homem moderno e aquelas oriundas da mente primitiva, fundamentando a existência de "imagens coletivas", repletas de "motivos mitológicos". Nesse sentido, os arquétipos se manifestam através de fantasias e podem se revelar através de “imagens simbólicas” (JUNG, S.D., p. 67-69). 
Grinberg, lendo Jung, conceitua arquétipo como uma espécie de matriz, isto é, "uma raiz comum a toda a humanidade a qual emerge a consciência" (GRINBERG, 1997, p. 134). Como camada mais profunda que o consciente, o inconsciente é a imagem do mundo, a qual a humanidade não cessa de alimentar a milhares e milhares de anos. Por isso, as imagens primordiais, sob as quais temos acesso, comum às diversas raças, culturas e civilizações, são chamados de arquétipos.

Para Durand (2012, p.62), “os arquétipos ligam-se a imagens muito diferenciadas pelas culturas e nas quais vários esquemas se vêm imbricar”. Eles podem ser apenas inferidos nas fantasias, nos mitos, nos sonhos, na literatura e nas diversas manifestações artísticas, mas jamais vistos. Por isso, no cordel brasileiro, em que a imaginação humana assume variadas roupagens, a influência dos arquétipos é passível de ser inferida.

Além disso, não se pode negar a relação entre os arquétipos e os mitos. De acordo com Karlo-Gomes (2017) e (2018), os arquétipos são como modelos de tempos imemoriais atualizadas em relatos míticos. A princípio, o mito é compreendido como uma projeção para o passado. Assim, algo só se torna real enquanto servir para repetir ou imitar um arquétipo (ELIADE, 1992), por isso mesmo é atemporal. É pelo fato de seguir esses modelos que o homem se manifesta como paradigmático por natureza. É também por meio da imitação dos arquétipos que o homem se projeta para uma época em que houve a revelação prototípica: a época mítica (ELIADE, 1992). Afinal, o homem sempre é mantido como fonte de interesse do mito. Segundo Eliade, "laicizados, degradados, camuflados, os mitos e as imagens míticas encontram-se por toda a parte: só é preciso reconhecê-los" (ELIADE, 2000, p. 25).

Lendo Durand, Danielle Pitta explica que um mito é um "relato fundante de uma cultura: ele vai estabelecer as relações entre as diversas partes do universo, entre homens entre si” (PITTA, 2017, p.23). Deparar-se com mitos em cordéis é encontrar inúmeros modelos de comportamento, dimensões pedagógicas etc., derivados de imagens atemporais: os arquétipos.

Portanto, levando em consideração essa "nebulosa complexa" e "movediça" (GIRARDET, 1987) onde habita uma constelação mitológica intensa e constante, torna-se relevante mergulhar na poética cordeliana, a fim de identificar essas matrizes do imaginário. Nesta perspectiva, este texto objetiva apresentar o conjunto mitológico-arquetípico do cordel: Antonio Conselheiro: o Profeta do sertão, de Rouxinol do Rinaré.

\section{A criança divina como mitologema do Profeta do Sertão}


O cordel de Rouxinol do Rinaré é inspirado na história de Antônio Vicente Mendes Maciel (1830-1897), natural de Quixeramobim - Ceará, conhecido como Antônio Conselheiro, em virtude de sua história junto ao Arraial de Canudos.

Antônio Conselheiro se fixa em Canudos, fazendo de Belo Monte um refúgio sagrado. A Guerra de Canudos foi oriunda da pressão dos proprietários de terras contra a comunidade, decorrente de interesse por mão-de-obra; assim como da Igreja contra a atuação nada ortodoxa do beato Conselheiro, e também, em virtude da pressão das próprias facções partidárias existentes na Bahia ${ }^{3}$. Liderado por Conselheiro, o conflito entre o movimento popular e o Exército Brasileiro durou de 1986 a 1987, matando grande parte da população (cerca de 25 mil pessoas) e a destruição total do povoado de Canudos. Sobre o ocorrido em Canudos, vale destacar as riquíssimas contribuições literárias de duas importantes obras: as crônicas escritas pelo jornalista Manoel Benício, O rei dos jagunços (1988); e o clássico da literatura nacional, Os sertões (1902), de Euclides da Cunha.

Figura 1: Capa de Kazane - Fortaleza - CE

\footnotetext{
${ }^{3}$ Cf.: VENTURA, Roberto. Canudos como cidade iletrada: Euclides da Cunha na urbs monstruosa. Revista de Antropologia, São Paulo, USP, V. $40 \quad \mathrm{n}^{\circ}$ 1, 1997. Disponível em: http://www.revistas.usp.br/ra/article/view/27066>. Acesso em: 27. Jan. 2016. pp. 167).
} 
G. Karlo-Gomes

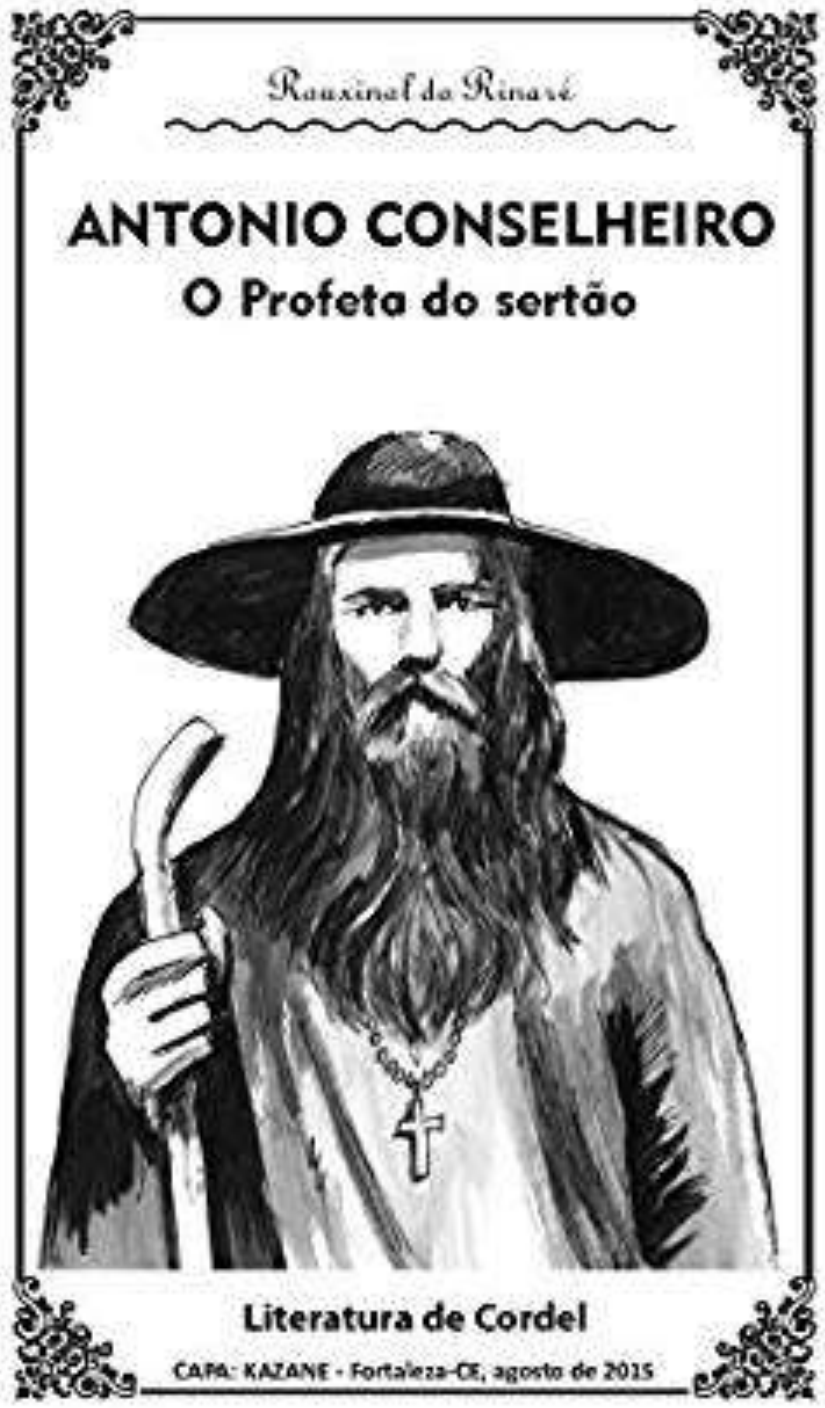

Fonte: (Capa de Kazane. In: RINARÉ, 2015)

Logo na capa em preto e branco (Figura 1), característica herdada das xilogravuras, nota-se a figura de Antonio Conselheiro com um cajado e um crucifixo. Sua barba longa, chapéu com abas bastante longas e seu olhar penetrante acentuam a figura profética anunciada no cordel.

Com efeito, o cordel de Rouxinol do Rinaré inicia remontando a origem de Antonio Conselheiro:

\author{
Nasceu Antonio Vicente \\ Mendes Maciel, assim, \\ Lá em Quixeramobim \\ Numa família decente \\ Nisso a história não mente
}


Falando de seu torrão;

Teve boa educação,

Cresceu honesto e ordeiro.

Foi Antonio Conselheiro

Um profeta do Sertão!

O Conselheiro sofreu

Na vida diversos danos

Órfão de mãe aos seis anos

Mais tarde o pai faleceu

Cuidava do povo seu

Com muita abnegação

Era um devoto cristão

E seguidor do Cordeiro

Foi Antônio Conselheiro

Um Profeta do Sertão!

(RINARÉ, 2015). ${ }^{4}$

A própria origem na literatura já remete a mitologia. Para Karl Kerényl (2011), tratase de uma mitologema, isto é, o conteúdo de uma narrativa, uma fundamentação ou fundação, ou seja, o conteúdo de um ato.

Para o fundador da psicologia analítica,

O mitologema é a linguagem verdadeiramente originária de tais processos psíquicos e nenhuma formulação intelectual pode alcançar nem mesmo aproximadamente a plenitude e a força de expressão da imagem mítica. Trata-se de imagens originárias cuja melhor expressão é a imagística (JUNG, 2015, p. 140).

No cordel de Rinaré, trata-se da figura de Antonio Conselheiro, em sua própria origem. É o ser humano na forma de uma figura original de boas qualidades morais, em berço de uma família exemplar. Mas, para fundamentar esse mitologema, o cordelista recorre à narração de sua história de vida como criança órfã. Trata-se do arquétipo da Criança Divina, uma figura muito presente nos contos de fadas, na Bíblia, nos variados mitos e na literatura universal. Esse arquétipo surge como uma criança abandonada ou órfã, cercada de perigos, mas preferida dos deuses.

A mistificação do nascimento de "Um Profeta do Sertão" é acentuada pelos sofrimentos a qual a criança foi sujeitada, por meio dos traços do mitologema da criança original: orfandade, solidão e força. É uma forma de descrever a figura de Antonio Vicente Mendes Maciel e sua trajetória mística como líder e conselheiro espiritual do povo de Arraial

\footnotetext{
${ }^{4}$ Não constam páginas.
} 
de Belo Monte. É assim que se constitui o mitologema do Profeta, repleta de imagens que têm raízes no profundo inconsciente coletivo. Essa obra de arte, (re) criada no curso do imaginário e de sua cultura, remonta às alegorias nascidas de imagens primordiais, inspirado na criança arquetipal; que reforça a carga simbólica do seu profetismo, de sua devoção cristã e "seguidor do cordeiro", ou seja, o próprio arquétipo do profeta.

Sobre a Criança Divina, é relevante acentuar, como explica Kerényl, que

\begin{abstract}
A infância e o destino de órfão das crianças divinas não foram feitos a partir do conteúdo da vida humana, mas a partir da matéria da vida do mundo. Aquilo que a mitologia parece ser biográfico é, de certo modo, uma anedota que o mundo conta a partir de sua própria biografia - conta em sonhos, em visões, mas de modo muito mais rico do que nestes, mas rico também do que foi alcançado pelas artes "profanas": na mitologia. Conceber as figuras mitológicas como alegorias de fenômenos naturais equivaleria a privar a mitologia de seu ponto central significativo e inspirador, privar daquele conteúdo do mundo válido de modo atemporal que se expressa de maneira mitológica nas imagens dos deuses [...] Um mitologema - assim como uma teoria altamente científica ou uma criação musical e, em geral, toda autêntica arte - fala, tem efeito e é válido por si mesmo. (KERÉNYL, 2011, p. 76).
\end{abstract}

O cordel de Rinaré, apoiado nesse mitologema, alegoriza a figura de um verdadeiro profeta do povo do Sertão. Refletindo a espontaneidade do inconsciente, essa literatura não está imune à ação dos arquétipos. Eles assumem significados matriciais na arte e na vida. A manifestação do motivo da criança prenuncia a vinda de uma espécie de Salvador dos sertanejos, numa heroificação dada pelo destino: o modelo exemplar de conselheiro e educador numa atmosfera mística de um andarilho erradio.

\title{
Conselheiro: Velho Sábio e Salvador
}

A travessia profética de Antonio do Conselheiro no cordel de Rinaré suscita ainda as densas potências oníricas do imaginário político. Isso porque seu destino incerto de criança órfã é um indício divino de um destino grandioso: uma espécie de salvador dos nordestinos. Tal recorrência se manifesta no prenúncio de que esse personagem histórico possuía o grande dom do ensinamento:

Por reveses do destino

Tornou-se errante andarilho

Mas tinha na alma um brilho, 
Na voz conselho e ensino, Que pelo chão nordestino Ganhou grande dimensão Uma grande multidão Logo seguiu seu roteiro Foi Antônio Conselheiro Um Profeta do Sertão!

(RINARÉ, 2015).

O brilho na alma é simbolicamente representativo do arquétipo do Velho Sábio. Para Jung (2012), é o arquétipo do conhecimento e do saber, da inteligência e da intuição, reunindo qualidades morais da benevolência e da solicitude. Essas se tornam as mais primorosas virtudes de um homem que se torna o arquétipo no próprio nome. Conselheiro atrai multidões em busca de ensinamentos e de solidariedade: ex-escravos, famintos, desabrigados e muitos outros que buscavam no Arraial de Velo Monte uma esperança de nova vida.

Assim, esse cordel suscita também o velho mito do Salvador, tão poderoso, atrativo e coerente, capaz de "fixar a atenção" e "reter a reflexão" (GIRARDET, 1987, p. 64). Isso decorre em função do processo de heroificação de Conselheiro para o povo desolado do sertão (KARLO-GOMES, 2017; 2018). Sobre esse fenômeno, Girardet acentua:

\begin{abstract}
Se o mito não pode deixar de conservar a marca do personagem em torno do qual ele se constrói, se, engrandecendo-os, tende a assegurar através do tempo a perenidade dos traços específicos que são os de sua fisionomia, não pode deixar, por outro lado, de depender ele próprio, em sua forma como em seu conteúdo, das circunstâncias, historicamente delimitadas, nas quais é elaborado. Todo processo de heroificação implica, em outras palavras, uma certa adequação entre a personalidade do salvador virtual e as necessidades de uma sociedade em um dado momento de sua história. $\mathrm{O}$ mito tende, assim, a definir-se em relação à função maior que se acha episodicamente atribuída ao herói, como uma resposta a uma certa forma de expectativa, a um certo tipo de exigência. (GIRARDET, 1987, p. 82).
\end{abstract}

Numa espécie de analogia, convém mencionar uma relevante contribuição sobre esse mito. Sintomaticamente intitulado Antônio Conselheiro e o mito do salvador ${ }^{5}$, o artigo de Leandro Vilar Oliveira busca associar o mito do Salvador e a figura de Antônio Conselheiro,

\footnotetext{
${ }^{5}$ Cf.: OLIVEIRA, Leandro Vilar. Antônio Conselheiro e o mito do salvador. História, imagens e narrativas. $\quad \mathrm{n}^{\circ} \quad 21 . \quad$ Outubro/novembro/2015. Disponível em: http://www.historiaimagem.com.br/edicao21outubro2015/conselheiro-salvador.pdf. Acesso em: 27 jan. 2015.
} 
considerando esse líder messiânico como o quarto modelo de Salvador, como mensurado por Girardet ${ }^{6}$, isto é, o modelo de

\begin{abstract}
Moisés ou o arquétipo do profeta. Anunciador dos tempos por vir, [...] lê na história aquilo que outros ainda não veem. Ele próprio conduzido por uma espécie de impulso sagrado, guia seu povo pelos caminhos do futuro. É um olhar inspirado que atravessa a opacidade do presente; uma vez, que vem de mais alto ou de mais longe, que revela o que deve ser visto e reconhecido como verdadeiro (GIRARDET, 1987 p. 78).
\end{abstract}

Na concepção de Jung, esse mito se estrutura pelo mesmo arquétipo do chefe, justo e sábio que se apodera do mundo comunista na esperança do Paraíso (JUNG, S.D.), apropriando-se de toda riqueza do imaginário nordestino. O simbólico Antônio Conselheiro reúne a esperança de um destino coletivo de bem-aventurança. (KARLO-GOMES, 2017; 2018). Assim, suscita-se um apelo ao Salvador através do que Girardet chama do "misterioso processo de heroificação", ou seja, a transmutação da história real ocorrida em Canudos e sua absorção no imaginário do cordel.

Sobre essa relação, é pertinente destacar o que Calazans comenta a respeito de Antônio Conselheiro: esse líder religioso era conhecido como "pai", "Bom Jesus Conselheiro". Sua feição magra, de poucas conversas, fez com que alguns o associassem ao Senhor dos Passos das procissões da Semana Santa, o que contribui para o seu endeusamento (CALASANS, 1969).

De qualquer modo, a ambiguidade do mito do Salvador reside no fato desse se consubstanciar no plano político e religioso. Analisando Jung e o Cristianismo, Christopher Bryant afirma que essa ambiguidade ocorre quando um símbolo religioso é efetivo ao pertencer a dois mundos: "o mundo do dia a dia, junto com as ideias e aspirações que todos sentem, e o mundo do inconsciente coletivo" (BRYANT, 1996, p. 93-94). É por meio de uma base arquetípica que a proximidade entre os dois mundos se torna possível, ou seja, a busca arquetípica de um Redentor, um justo, um mensageiro.

Nesse sentido, no cordel de Rinaré, Antônio Conselheiro se torna uma figura de bondade, de sabedoria e mistério. Apelando pela poética do universo simbólico-messiânico, o autor configura um mitologema do "Profeta do sertão", dotando a história de Conselheiro

${ }^{6}$ Girardet considera quatro modelos de Salvador na História: cônsul romano, Cincinnnatus (519-430 a. C); o conquistador e herói, Alexandre, o Grande (356-323 a. C.); o legislador que reestabelece a ordem e a justiça, Sólon de Atenas (638-558 a. C.); e o profeta presente na Bíblia de tradição judaico-cristã: Moisés. (OLIVEIRA, 2015, p. 9). 
com fortes cargas mitológicas do salvador do povo sofredor do Nordeste. Essa atmosfera é criada graças ao imaginário coletivo do arquétipo do Velho Sábio, em suas virtudes como um conselheiro espiritual; do mito do Salvador, nutrindo o povo com a esperança para um destino de bem-aventuranças em Arraial de Canudos; e do nascimento da Criança Divina, anunciando um destino misterioso, iluminado e atemporal do "Conselheiro do sertão".

\section{Referências}

BENÍCIO, Manoel. O rei dos jagunços. Chronica histórica e de costumes sertanejos sobre acontecimentos de Canudos. Brasília: Senado Federal, 1997.

BOLEN, Jean Shinoda. As deusas e a mulher: nova psicologia das mulheres. São Paulo: Paulus, 1990.

BRYANT. Christopher. Jung e o Cristianismo. Trad. Cecília Camargo Batalotti. São Paulo: Edições Loyola. 1996.

CALASANS, José. Notícias de Antônio Conselheiro. Vol. 56. Salvador: Centro de Estudos Baianos, 1969.

CUNHA, Euclides da. Os Sertões. Volume 1. São Paulo: Ministério da Cultura. Fundação Biblioteca Nacional. Departamento Nacional do Livro, 1901. Disponível em:

http://www.dominiopublico.gov.br/pesquisa/DetalheObraForm.do?select_action=\&co_obr $\underline{\mathrm{a}=2163}$. Acesso em 29. fev. 2016.

DIÉGUES JÚNIOR, Manuel. Ciclos temáticos na literatura de cordel. In.: Literatura Popular em Verso - Estudos. Tomo I. Rio de Janeiro: Casa de Rui Barbosa, 1973.

DURAND, Gilbert. As estruturas antropológicas do imaginário: introdução a arquetipologia geral. Trad. Hélder Godinho. São Paulo: Martins Fontes, 2012.

ELIADE, Mircea. Mitos, Sonhos e Mistérios. Trad. Samuel Soares. Lisboa-Portugal: Edições 70, 2000.

ELIADE, Mircea. O Sagrado e o Profano. Trad. Rogério Fernandes. São Paulo: Martins Fontes, 1992.

GIRARDET, Raoul. Mitos e Mitologias Políticas. Trad. Maria Lucia Machado. São Paulo: Companhia das Letras, 1987.

GRIMBERB, Luiz Paulo. Jung: o homem criativo. São Paulo: FTD, 1997.

KARLO-GOMES, Geam. A antinomia comunismo-cristianismo: leitura mitológicoarquetípica da obra Assunção de Salviano. Pernambuco: Edupe, 2018. 
KARLO-GOMES, Geam. Assunção de Salviano na antinomia comunismocristianismo: a busca do paraíso perdido. 2017. 192f. Tese ( Programa de Pós-

Graduação em Literatura e Interculturalidade - PPGLI) - Universidade Estadual da Paraíba, Campina Grande, PB. Disponível em: http://tede.bc.uepb.edu.br/jspui/handle/tede/2948. Acesso em: 28. Jun. 2021.

JUNG, Carl Gustav. Espiritualidade e Transcendência. Seleção e edição de Brigitte Dorst. Trad. Nélio Schneider. Petrópolis, RJ: Vozes, 2015.

JUNG, Carl Gustav. O Homem e seus Símbolos. Trad. Maria Lúcia Pinho. $5^{\mathrm{a}}$ ed. Rio de Janeiro: Nova Fronteira S. A., S.D.

JUNG, Carl Gustav. Os arquétipos e o inconsciente coletivo. Trad. Maria Luiza Appy e Dora Mariana R. Ferreira da Silva. Petrópolis, RJ: Vozes, 2012.

JUNG, Carl Gustav; KERÉNYI, Karl. A Criança Divina: uma introdução à essência da mitologia. Trad. Vilmar Schneider. Petrópolis, RJ: Vozes, 2011.

LUCIANO, Aderaldo. Apontamentos para uma História crítica do cordel brasileiro. Rio de Janeiro: Edições Adaga - São Paulo: Editora Luzeiro, 2012.

MARK, Margaret; PEARSON, Carol S. O Herói e o Fora-da-Lei. São Paulo: Pensamento Cultrix LTDA, 2001.

MAFFESOLI, Michel. O imaginário é uma realidade. (Entrevista a Juremir Machado da Silva). In.: Revista Famecos, mídia, cultura e tecnologia, ${ }^{\circ}$ 15. Porto Alegre: Edipucrs, 2001. p.74-82.

OLIVEIRA. Leandro Vilar. Antônio Conselheiro e o mito do salvador. História, imagens e narrativas. $\mathrm{n}^{\circ} 21$. Outubro/novembro/2015. Disponível em:

http://www.historiaimagem.com.br/edicao21outubro2015/conselheiro-salvador.pdf. Acesso 27. Jan. 2015.

RINARÉ, Rouxinol. Antônio Conselheiro: o Profeta do sertão. Literatura de cordel. Fortaleza - CE, agosto de 2015. Disponível em: https://www.amazon.com.br/ANTONIOCONSELHEIRO-Um-Profeta-Sert\%C3\%A3o-ebook/dp/B014V3ZKT2. Acesso: 20. Out. 2017.

VENTURA, Roberto. Canudos como cidade iletrada: Euclides da Cunha na urbs monstruosa. Revista de Antropologia, São Paulo, USP, V. 40 n 1, 1997. Disponível em: http://www.revistas.usp.br/ra/article/view/27066>. Acesso em: 27. Jan. 2016. pp. 167

WOOLGER, Jennifer Barker; WOOLGER, Roger J. A Deusa Interior: Um guia sobre os eternos mitos femininos que moldam nossas vidas. São Paulo: Cultrix, 2007.

Artigo recebido em: 25/06/2021

Artigo aceito para publicação em: 25/06/2021 